\title{
Recorregut de recerca geològica i mineralògica per la comarca de la Noguera: des de Vilanova de Meià a Figuerola de Meià, Fontllonga, Baronia de Sant Oïsme i a la Font de les Bagasses
}

Josep Maria Mata-Perelló

Joaquim Sanz Balagué

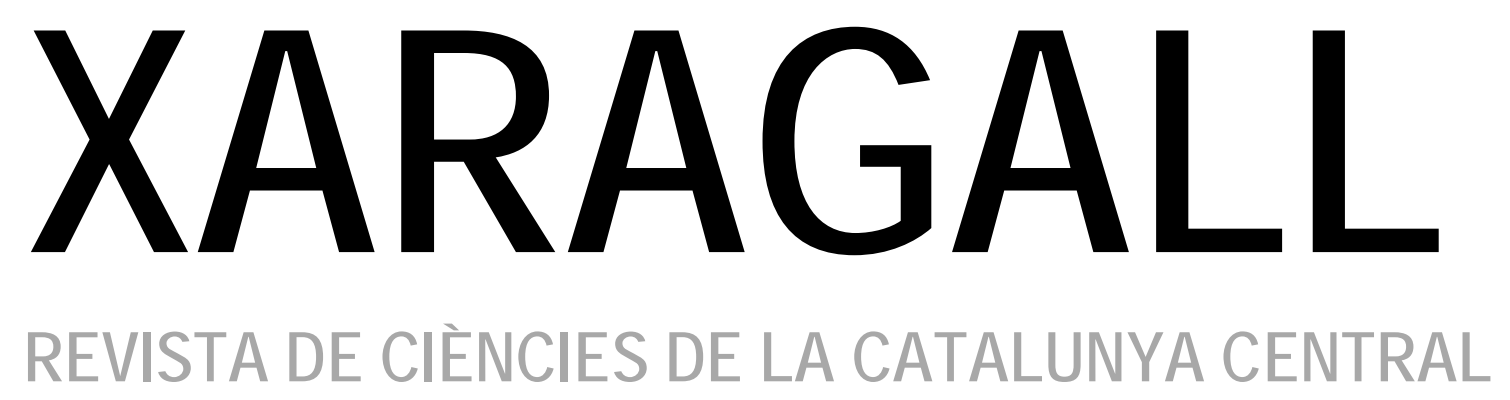

n. 8

AGOST 2015

Com citar l'article: Mata-Perelló, JM.; Sanz Balaguer, J. Recorregut de recerca geològica i mineralògica per la comarca de la Noguera: des de Vilanova de Meià a Figuerola de Meià, Fontllonga, Baronia de Sant Oïsme i a la Font de les Bagassesper. A: XARAGALL. Revista de Ciències de la Catalunya Central. 2015. (n.8). ISSN 2013-4479 DL: B.21483-2009. DOI 


\title{
RECORREGUT DE RECERCA GEOLÒGICA I MINERALÒGICA PER LA COMARCA DE LA NOGUERA: DES DE VILANOVA DE MEIÀ A FIGUEROLA DE MEIÀ, FONTLLONGA, BARONIA DE SANT OÏSME I A LA FONT DE LES BAGASSES
}

\author{
Josep Maria Mata-Perelló \\ Museu de geologia Valentí Masachs, Escola Politècnica Superior d'Enginyeria de Manresa \\ (EPSEM), Universitat Politècnica de Catalunya · BarcelonaTech (UPC), 08272 Manresa, Spain
}

\section{Joaquim Sanz Balagué}

Departament d'Enginyeria Minera i Recursos Naturals (EMRN), Escola Politècnica Superior d'Enginyeria de Manresa (EPSEM), Universitat Politècnica de Catalunya - BarcelonaTech (UPC), 08272 Manresa, Spain

Paraules clau: Sistema Pirinenc, Patrimoni miner

\section{Resum}

Itinerari realitzat el 9 d'agost de 2014. En aquesta ocasió, el recorregut de l'itinerari discorrerà, en la seva quasi totalitat pel Sistema Pirinenc, i més concretament ho farà per la seva Unitat Sudpirinenca Central (també anomenada com a les Serres Exteriors Prepirinenques).

En concret, el recorregut del present itinerari passarà per dos dels seus sectors més representatius del Sistema Pirinenc; concretament pel Mantell del Montsec i pel Mantell de la Serra de Sant Mamet, situat al Sud de l'anterior. De fet, el recorregut de l'itinerari discorrerà per la zona de contacte de les dues estructures pirinenques, entre Vilanova de Meià i les immediacions de la Palanca, al Nord de la Baronia de Sant Oïsme.

Tot i així, el darrer tram del recorregut, l'efectuarà ja íntegrament pel Mantell del Montsec, per les immediacions de la Font de les Bagasses, per on finalitzarà aquest recorregut de l'itinerari.

Per altra banda, el recorregut de l'itinerari discorrerà íntegrament per una sola comarca, per la de la Noguera, des de principi a fi del mateix. 


\section{Objectius fonamentals}

Es centraran en els aspectes geològics, geomorfològics i mineralògics que apuntarem a continuació:

1. Estudi de l'estructura materials del Mantell del Montsec (situats dintre dels relleus prepirinencs de la Unitat Sud-pirinenca Central). En aquest recorregut anirem transitant al peu del mateix, tret del darrer trajecte que realitzarem per anar a la Font de les Bagasses, que transitarem íntegrament pel Mantell del Montsec.

2. Estudi i observació dels materials mesozoics (del Juràssic i sobretot del Cretàcic), i del cenozoic (fonamentalment de l'Eocè i de l'Oligocè), que formen part dels relleus del mantell acabats d'esmentar al paràgraf anterior. I, tanmateix dels materials oligocènics postorogènics que ocasionalment els cobreixen.

3. Estudi de l'estructura materials del Mantell de la Serra de Sant Mamet (situats també dintre dels relleus prepirinencs de les Serres Prepirinenques Exteriors). En aquest itinerari, nosaltres anirem circulant al Nord del mateix, per la zona de contacte amb el Mantell del Montsec, situat al Nord.

4. Estudi i observació dels materials mesozoics (del Juràssic i sobretot del Cretàcic), i del cenozoic (fonamentalment de l'Eocè i de l'Oligocè), que formen part dels relleus del Mantell de la Serra de Sant Mamet.

5. Observació de les relacions existents, dintre de la zona per la qual discorre el recorregut de l'itinerari, entre les zones abans esmentades, del Sistema Pirinenc. (concretament entre el Mantell del Montsec i el Mantell de la Serra de Sant Mamet.

6. Reconeixement de diverses mineralitzacions situades al llarg del recorregut del present itinerari.

7. Observació dels diferents indrets relacionats amb el patrimoni geològic que anirem trobant al Ilarg del recorregut d'aquest itinerari.

8. Observació dels diferents indrets relacionats amb el patrimoni miner, si s'escau, que anem trobant al llarg del recorregut d'aquest itinerari.

\section{Antecedents}

En relació amb aquest itinerari geològico-mineralògic, existeixen molts pocs antecedents; de fet, sols farem esment dels següents antecedents nostres: MATA-PERELLÓ (1996. 1999, 2002, 2004, 2010, 2011, 2012 y 2014). Es tracta, en tots els casos, d'itineraris parcials, coincidents en part amb el que ara tractarem.

Pel que fa a les mineralitzacions que veurem en aquest itinerari, cal dir que també ja estat prèviament descrites per nosaltres mateixos en MATA-PERELLÓ (1991). En aquest treball es fa referència a les mineralitzacions catalanes en general, parlant-se també de les situades al llarg d'aquest itinerari; i que es distribueixen tant per la Noguera, com pel proper Pallars Jussà. 
I pel que fa a l'estructura geològica, ens remetérem a RIBA et altri (1976), i a GUIMERÀ et altri (1992). En ambdós treballs, es fa referència a l'estructura geològica dels Països Catalans. Per d'altra banda, també ens cal fer referència de ROSELL (1970); així com de l'IGME (1994).

Finalment, cal dir que tots aquests treballs, es trobaran relacionats, per estricte ordre alfabètic, dintre de l'apartat dedicat a les REFERĖNCIES BIBLIOGRÀFIQUES, al qual es remetem, pel que s'escaigui.

\section{Recorregut de l'itinerari}

Aquest itinerari, s'iniciarà per les immediacions de la població de Vilanova de Meià, per on es farà la primera aturada. Tot seguit, per la carretera LV - 9131, el recorregut es dirigirà cap a Santa Maria de Meià, fent-se una nova aturada.

A partir d'aquí, el recorregut continuarà per una "carretera blanca", sense asfaltar, que s'anirà dirigint cap a ponent. Així es passarà per: Peralba i Figuerola de Meià. En aquest tram s'efectuarà una aturada al Coll d'Orenga.

Des del darrer poble esmentat, ara per una carretera asfaltada s'arribarà al Coll de Fontllonga. Aquí s'entroncarà amb la carretera catalana C - 13 (procedent de Camarasa), per la qual caldrà continuar cap el Nord. Així, es passarà pro de Fontllonga i s'arribarà a la Baronia de Sant Oïsme. En aquest tram es faran diverses aturades.

Després, el recorregut es dirigirà (seguint cap el Nord) cap a la cruïlla amb la carretera procedent d'Ager, la $C-12$. I, finalment, es seguirà per aquest primer vial (per la $C-13$ ), per tal d'arribar a la Font de les Bagasses, on finalitzarà el recorregut d'aquest itinerari. En aquest darrer tram es faran diverses aturades.

\section{Advertiments previs}

Com en altres recorreguts de RECERCA GEOLÒGICA I MINERALÒGICA... si es disposa del temps suficient, poden efectuar-se passant per totes les parades i filloles. En cas contrari, recomanem prescindir de les anomenades PARADES - CONDICIONALS.

Per altra banda, cal tenir cura del coneixement de l'estat de conservació d'alguns dels trams dels camins a recórrer. En concret, del que ens ha de conduir des de les immediacions de Vilanova de Meià i de Santa Maria de Meià cap a Figuerola de Meià i cap a la Fontllonga.

Per altra banda, i a l'igual que en altres recorreguts semblants, recomanem tenir el màxim de cura i de respecte, entorn de la Natura que ens rodeja. 


\section{Descripció de l'itinerari}

Com ja és habitual, farem una sèrie de PARADES (o de ESTACIONS). En cada una d'elles, farem esment del terme municipal on es troben (en el cas de que no quedi clar, al situar la parada), així com del número del MAPA TOPOGRÁFICO NACIONAL (a escala 1:50.000), que indicarem entre parèntesi.

Per altra banda, en cada una de les parades indicarem el nom del municipi, en el qual es troben situades. També indicarem el nombre de la comarca en el qual es troba situada. En aquesta ocasió, utilitzarem els dos següents fulls: 290 (Isona) i 328 (o d'Artesa de Segre). Tots aquests fulls, han estat publicats per Instituto Geogràfico y Catastral de España. Tanmateix podem utilitzar es fulls de I'Institut Cartogràfic de Catalunya, dedicats a la comarca del Pallars Jussà i a la de la Noguera.

Així doncs, la relació general ordenada de les aturades que composen aquest itinerari, es el següent:

\subsection{Parada 1. SORTIDA DE VILANOVA DE MEIÀ, CAP A SANTA MARIA DE MEIÀ, CARRETERA LV - 9131, (terme municipal de Vilanova de Meià, comarca de la Noguera). (Full 290).}

El recorregut de l'itinerari, el començarem al bell mig de la població de Vilanova de Meià. Des d'aquí, ens caldrà sortir per la carretera L - 913 (procedent de l'Hostal Roig) per tal d'anar cap a la sortida del poble, a la cruïlla amb la carretera LV - 9131, la qual es dirigeix cap a Santa Maria de Meià. En aquesta cruïlla farem la primera aturada de l'itinerari, a $1 \mathrm{Km}$ del centre de la població, aproximadament.

En aquest recorregut, hem estat circulant pels materials cenozoics que formen part de l'extrem oriental del Mantell de la Serra de Sant Mamet. Al Nord, d'on ara som, s'observa I'encavalcament del Mantell del Montsec sobre els materials que estem veient ara, a l'indret de I'aturada.

Així, aquest encavalcament dels materials mesozoics del Mantell del Montsec es produeix sobre nivells de calcolutites ocres i de gresos, que pertanyen a la Formació Solsona. Molt sovint, aquests materials es troben recoberts per nivells detrítics de conglomerats de la Formació Berga.

\subsection{Parada 2. IMMEDIACIONS DE SANTA MARIA DE MEIÀ, CAMÍ DE DE LA CABROA, (Santa Maria de Meià, terme municipal de Vilanova de Meià, comarca de la Noguera). (Full 328).}

Després de realitzar l'aturada anterior, cal continuar per la carretera que es dirigeix cap a ponent, la $L$ - 3191. Així, aviat arribarem a la població de Santa Maria de Meià (en uns 2’ 5 $\mathrm{Km}$ ). I més endavant a l'inici del Camí de la Cabroa, per on farem la present aturada, a uns 3 $\mathrm{Km}$ de la parada anterior.

En aquest recorregut, entre Vilanova de Meià i Santa Maria de Meià, haurem estat circulant al Sud del Mantell del Montsec, passant sempre per la que podríem denominar Depressió de Vilanova de Meià - la Garzòla, entre afloraments de materials cenozoics, fonamentalment de I'Eocè Inferior, de caràcter eminentment deltaic. Per d'altra banda, aquesta conca s' haurà anat fent cada cop menys extensa a mida que ens hem allunyat de Vilanova de Meià.

Per altra banda, cap I Sud d'on ara ens trobem, al Sud de Garzòla, es veuen els relleus septentrionals de I'encavalcament d'Alentorn. Aquets relleus constitueixen el límit meridional 
de la depressió on ara estem situats. Tanmateix, al SW es poden veure els relleus de la Vall d'Ariet, que constitueix l'extrem oriental de la Serra de Sant Mamet.

\subsection{Parada 3. COLL D'ORENGA O COLL DE PERALBA, (Santa Maria de Meià, terme municipal de Vilanova de Meià, comarca de la Noguera). (Full 328).}

Després de realitzar l'aturada anterior, cal continuar cap a ponent, seguint la carretera LV 9131, que ara és una "carretera blanca", un vial sense asfaltar, però en bones condicions. Així, ens anirem apropant al Coll d'Orenga (o Coll de Peralba). En arribar-hi, farem una nova aturada dintre d'aquest itinerari. Així, haurem efectuat un recorregut molt proper als $8-9 \mathrm{Km}$, des de la parada anterior.

En aquest recorregut, ens hem allunyat de la que podríem denominar Depressió de Vilanova de Meià - la Garzòla. Així, per una banda ens hem aproximat al Mantell del Montsec, cap el Nord; i per d'altra hem aproximat al Mantell de la Serra de Sant Mamet, situat al Sud. De fet, estem circulant per la zona de contacte entre els dos mantells, per l'encavalcament del primer sobre el segon.

Així, en aquest indret, ens trobem clarament a la zona de contacte, a l'encavalcament. Per d'altra banda es fa força ostensible el flanc septentrional de I'Anticlinal de la Serra de Sant Mamet, el qual cabussa cap on som ara, cap al Nord.

Tanmateix cal dir, que aquest és un indret on es fa palesa una extraordinària visió de diferents indrets de la geologia i de la geografia de Catalunya; així, mirant cap a llevant (o millor cap el ESE), es fan palesos a la llunyania els relleus de la muntanya de Montserrat.

Més propers, es fan palesos els relleus dels voltants de Vilanova de Meià; concretament de I'anomenat Montsec de Meià.

I, mirant cap a ponent, es fa força palès el Sinclinal de la vall d'Ager; així com el Montsec d'Ager.

Finalment, cal dir que aquest coll constitueix una clara divisòria d'aigües entre la vall de la Noguera Pallaresa (a llevant) i la vall del Segre (a ponent).

\subsection{Parada 4. BAIXADA DEL COLL DE FONTLLONGA, (Fontllonga, terme municipal de Camarasa - Fontllonga, comarca de la Noguera). (Full 328).}

Després de realitzar l'aturada anterior, cal continuar cap a ponent, seguint la carretera LV 9131, anant sempre cap a ponent. Aviat es passarà per la població de Peralba i més endavant s'arribarà a Figuerola de Meià. A partir d'aquí, la carretera ja està asfaltada. Continuant per ella, s'arribarà al Coll de Fontllonga. En arribar-hi es trobarà la carretera $\mathrm{C}-13$ (procedent de Camarasa). A nosaltres ens caldrà agafar-la, per tal d'anar cap el Nord. Així baixarem el coll abans esmentat. En baixar-lo, farem una nova aturada, a uns $10 \mathrm{~km}$ de la parada anterior i a poc més de 1 ' $5 \mathrm{Km}$ de la cruilla de carreteres.

En aquest recorregut, hem anat circulant prop de l'encavalcament del Mantell del Montsec sobre el Mantell de la Serra de Sant Mamet, tot i que ens haurem apropat molt a aquesta unitat, on ara ens trobem situats.

En aquest lloc de la parada, ens trobem en una antiga pedrera de calcàries, Els materials explotats, han estat emprats com a àrids per la construcció, donat el conjunt de fractures que presentes, I'explotació va estar força senzilla. Aquesta, es troba situada prop de I'antic $\mathrm{Km}$ $24^{\prime} 6$ de l'antiga carretera. Aquestes calcàries pertanyen al Cretàcic Superior i es troben situades al flanc septentrional de l'Anticlinal de la Serra de Sant Mamet. 
Aquí es pot fer observació de la intensa fracturació de les calcàries mesozoiques del Cretàcic. (fotografia 1).

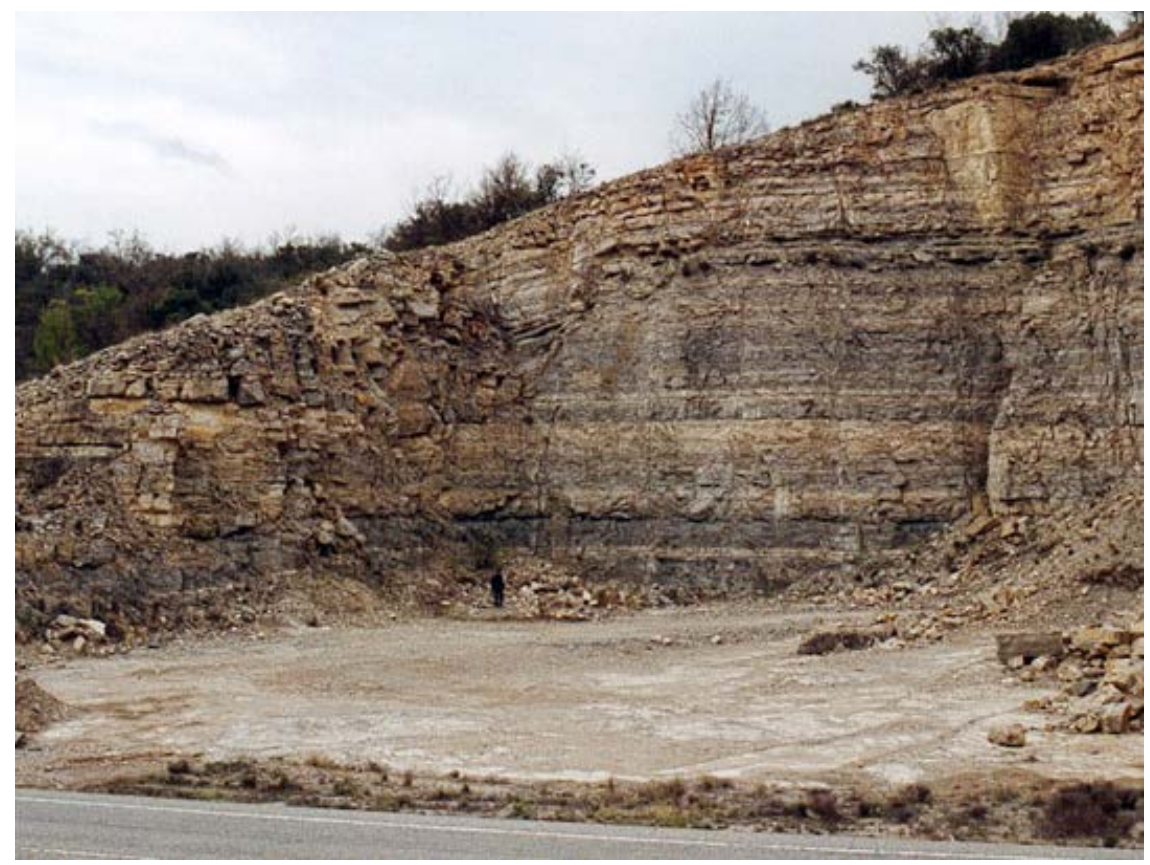

Fotografia 1. Un aspecte de pedrera i de la fracturació de les calcàries explotades. Baixada del Coll de Fontllonga, cap el Nord

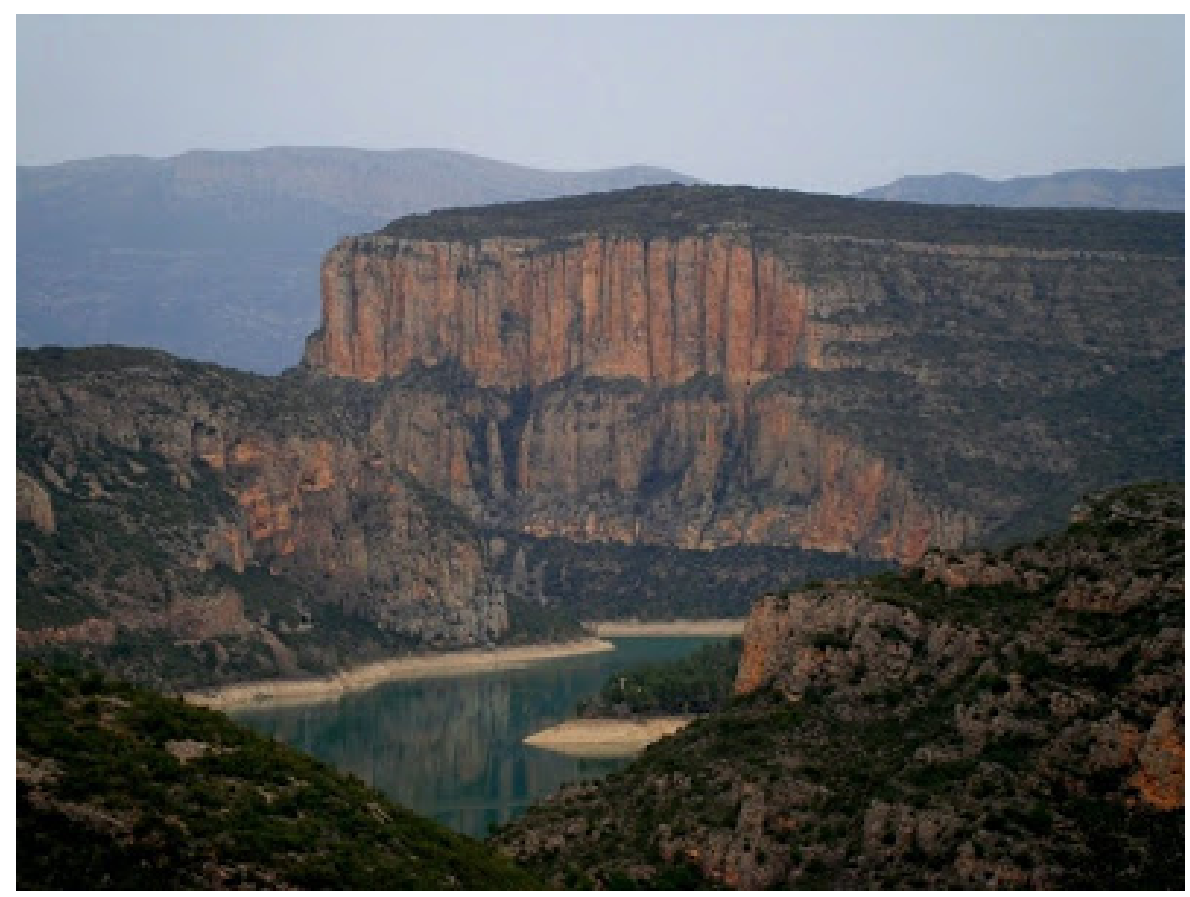

Fotografia 2. Un aspecte del Doll 


\subsection{Parada 5. ENTRADA A FONTLLONGA, (Fontllonga, terme municipal de Camarasa - la Fontllonga, comarca de la Noguera). (Full 328).}

Des de la parada anterior cal continuar per la carretera autonòmica C-13, per tal d'anar cap al Nord, cap el trencall de Fontllonga i cap a la Baronia de Sant Oïsme. En arribar al trencall del poble de Fontllonga, ens caldrà agafar-ho, per tal d'anar-hi. En arribar, ens caldrà fer una nova aturada després d'un recorregut proper als $3 \mathrm{Km}$, des de la parada anterior.

En aquest Ilarg recorregut, hem anat veient diverses estructures i materials. Aquests materials formen part del flanc septentrional de l'Anticlinal de la Serra de Sant Mamet. Per on ara estem situats. En aquest recorregut, haurem vist afloraments dels materials del Garumnià, per tot arreu. Aquests afloraments es troben situats per sobre de les calcàries del Cretàcic Superior que constitueixen el nucli de l'anticlinal abans esmentat.

Per altra banda, des de l'indret de l'aturada es pot veure l'encavalcament del Mantell del Montsec, situant-se per sobre de la Unitat de la Serra de Sant Mamet.. El primer es situa al Nord i el segon al Sud

Al mateix temps, des d'aquest indret, on ara ens trobem situats es pot veure una bona perspectiva de I'engorjament del Doll, produït en travessar el Riu Noguera Pallaresa la Serra de Sant Mamet. (fotografies 2 i 3).

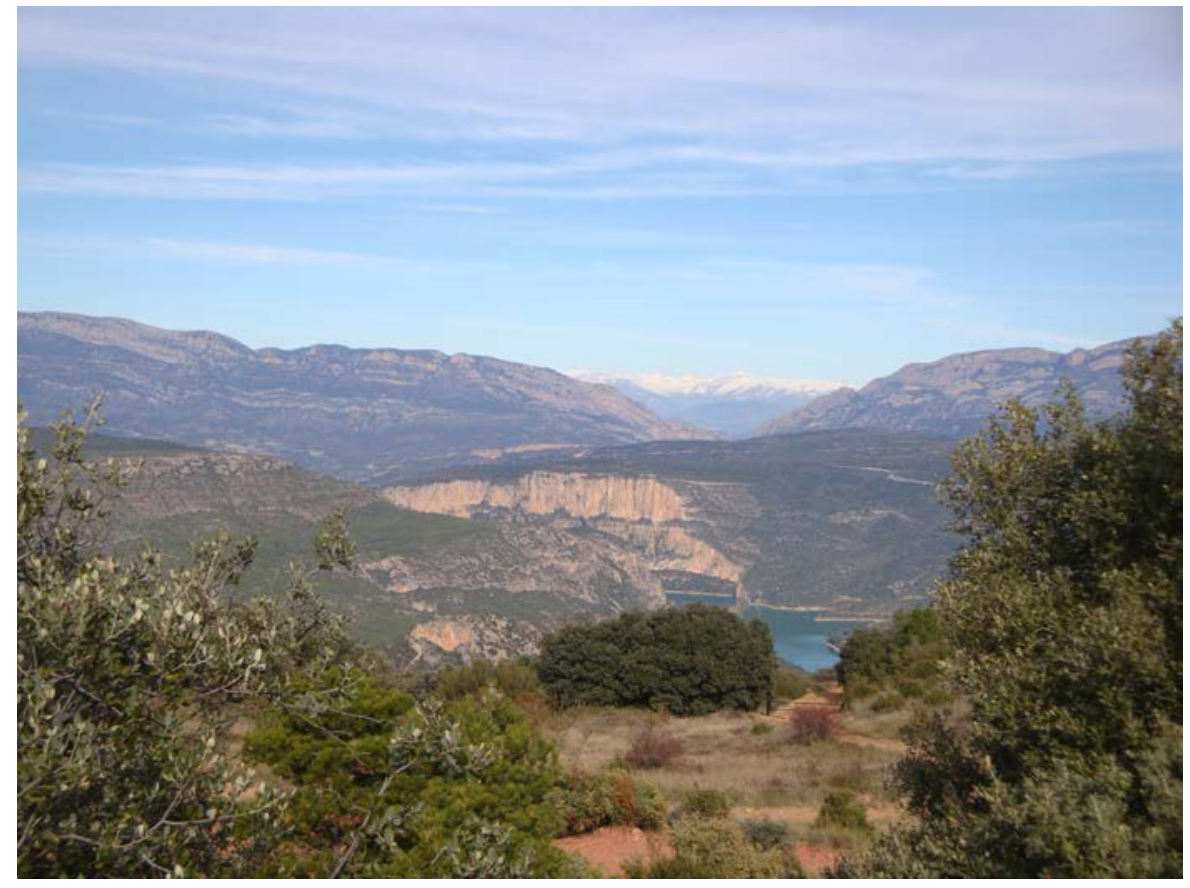

Fotografia 3. Un aspecte llunyà del Doll, des del Coll de Porta. Serra de Motroig

Permet veure: el Doll, el Monsec i fins i tot la Zona Axial Pirinenca, nevada 


\subsection{Parada 6. IMMEDIACIONS DE LA BARONÍA DE SANT OÏSME, (Sant Oïsme, terme de Camarasa - la Fontllonga, comarca de la Noguera). (Full 328).}

Després de fer l'aturada anterior, cal retornar a la carretera $C-13$, per tal de continuar cap amunt, remuntant la vall del Noguera Pallaresa. Aviat arribarem a l'indret on es troba I'antic poble de la Baronia de Sant Oïsme. En arribar-hi, farem una nova aturada, molt prop de la torre de I'antic castell. Així, des de la parada anterior, haurem efectuat un recorregut molt proper als $6{ }^{\prime} 5 \mathrm{Km}$, per tal d'arribar fins aquí.

En aquest recorregut, des de la parada anterior, hem continuat circulant pel flanc septentrional de I'Anticlinal de la Serra de Sant Mamet, a l'igual que als recorreguts anteriors. Així, hem anat trobant afloraments dels materials del Garumnià. Aquests materials es troben constituïts per gresos i per calcolutites versicolors, generalment de tonalitats ocres, grises i liles; tanmateix hi ha diverses intercalacions calcàries de tonalitats molt clares, les quals contenen abundants restes fòssils. Aquests materials es fan força ostensibles entre els antics Km 26 i 27 de la carretera procedent de Camarasa.

Més endavant, per sobre d'aquests materials del Garumnià, del trànsit del Cretàcic al Paleocè, hem començat a trobar nivells que ja pertanyen al Cenozoic inferior. Es tracta de calcolutites $i$ de gresos de vegades rogenques i de vegades grisenques, que contenen nivellets de guix molt ocasionalment.

Després, haurem començat a trobar afloraments dels gresos i calcolutites grises de l'Eocè Inferior, prop de l'indret de l'aturada. Aquests materials els anirem trobant després, e el recorregut cap a la parada anterior. Així, aquests materials ja es fan ostensibles prop dels antics $\mathrm{Km} 29$ i 30.

Per altra banda, es d'aquest indret, es pot fer una bona observació del petit congost, per on es situa el poblet de Sant Oïsme. Tanmateix es pot veure os es situava l'antic poblet d'Oroners, cobert totalment per les aigües de l'embassament de Camarasa.

\subsection{Parada 7. CRUÏLLA DE LES CARRETERES C - 12 i C- 13, INICI DE LA CARRETERA A ÀGER, (Sant Oïsme, terme de Camarasa - la Fontllonga, comarca de la Noguera). (Full 328).}

Després de fer l'aturada anterior, cal retornar a la carretera $C-13$, per tal de continuar cap amunt. Aviat arribarem a la cruilla amb la carretera C - 12 (la qual procedeix d'Ager i que conclou aquí). En trobar la cruïlla, ens caldrà passar a I'altra banda de la Noguera Pallaresa; en realitat de l'embassament de Camarasa. Un cop a l'altre cantó, podem fer un breu recorregut, fins arribar a un indret on es pot parar, a uns 200 metres del pont. Aquí farem una nova aturada, a uns $4 \mathrm{Km}$ de la parada anteriorment feta a la Baronia de Sant Oïsme,

En aquest recorregut, hem anat trobant afloraments dels sediments eocènics de tonalitats grisenques, que ja hem vist prop de la Baronia de Sant Oïsme. Es tracta dels afloraments de la Formació Passarel·la, constituïda per nivells de gresos i de calcolutites grisenques. Així, en bona part d'aquest recorregut, hem trobat afloraments d'aquests darrers materials; es tracta de sediments dipositats en un medi litoral costaner, això es pot afirmar per l'existència d'estructures sedimentàries de retreballament del sediment, en aquest cas el més palpable són els ripples d'oscil-lació, aquestes petites dunes simètriques que tan acostumats estem a veure en les platges actuals i que es formen per l'acció de les onades sobre l'arena de la platja. 
Per altra banda, tot i situar-nos en el flanc septentrional del Anticlinal de la Serra de Sant Mamet, en arribar a l'indret de la Passarel.la, haurem sobrepassat el pla axial d'un sinclinal molt ben definit. Es tracta de I'anomenat Sinclinal d'Ager. Aquest element estructural defineix perfectament la Vall d'Ager. A l'indret on hem sobrepassat el pla axial del plec, afloren els materials eocènics esmentats al paràgraf anterior. (fotografia 4).

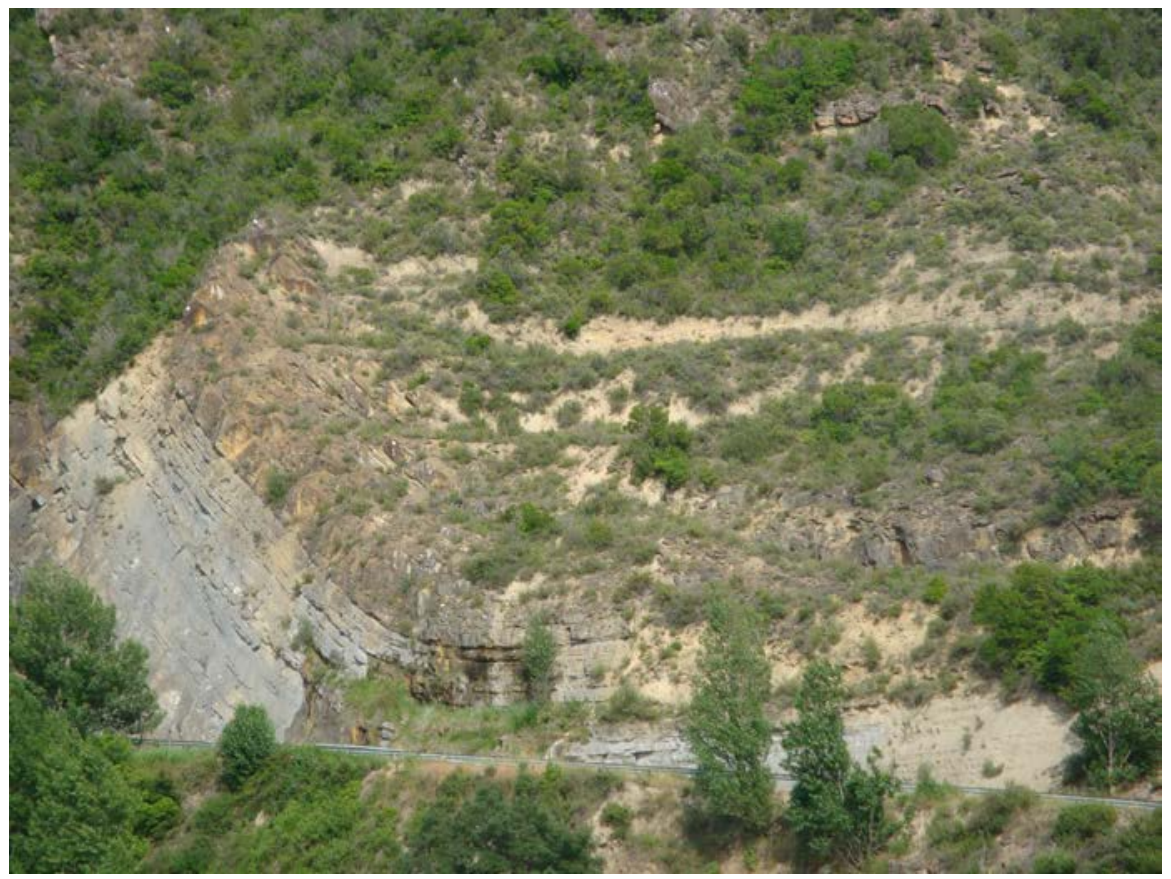

Fotografia 4. Un aspecte del Sinclinal d'Ager, amb I'aflorament dels materials eocènics de la Formació Passarel·la, amb nivells de calcolutites i gresos de tonalitats grisenques.

Aquesta vall es troba al Nord de la Serra de Montclús i al Sud del Montsec d'Ager. Efectivament, la primera es un anticlinal, que ve a constituir la continuació de l'Anticlinal de la Serra de Sant Mamet, separant els dos anticlinals el Noguera Pallaresa, però de fet és el mateix accident tectònic, encara que amb una alçada més minsa. Mentre que a l'altra banda de la vall es situa el Montsec d'Ager, el qual és una part del mateix mantell que hem anat seguint des de Vilanova de Meià: el Mantell del Montse. I entre les dues alineacions (de direcció $\mathrm{E}-\mathrm{W}$ ) es situa la Vall d'Ager, tot seguint la direcció del sinclinal del mateix nom. (fotografia 5). 


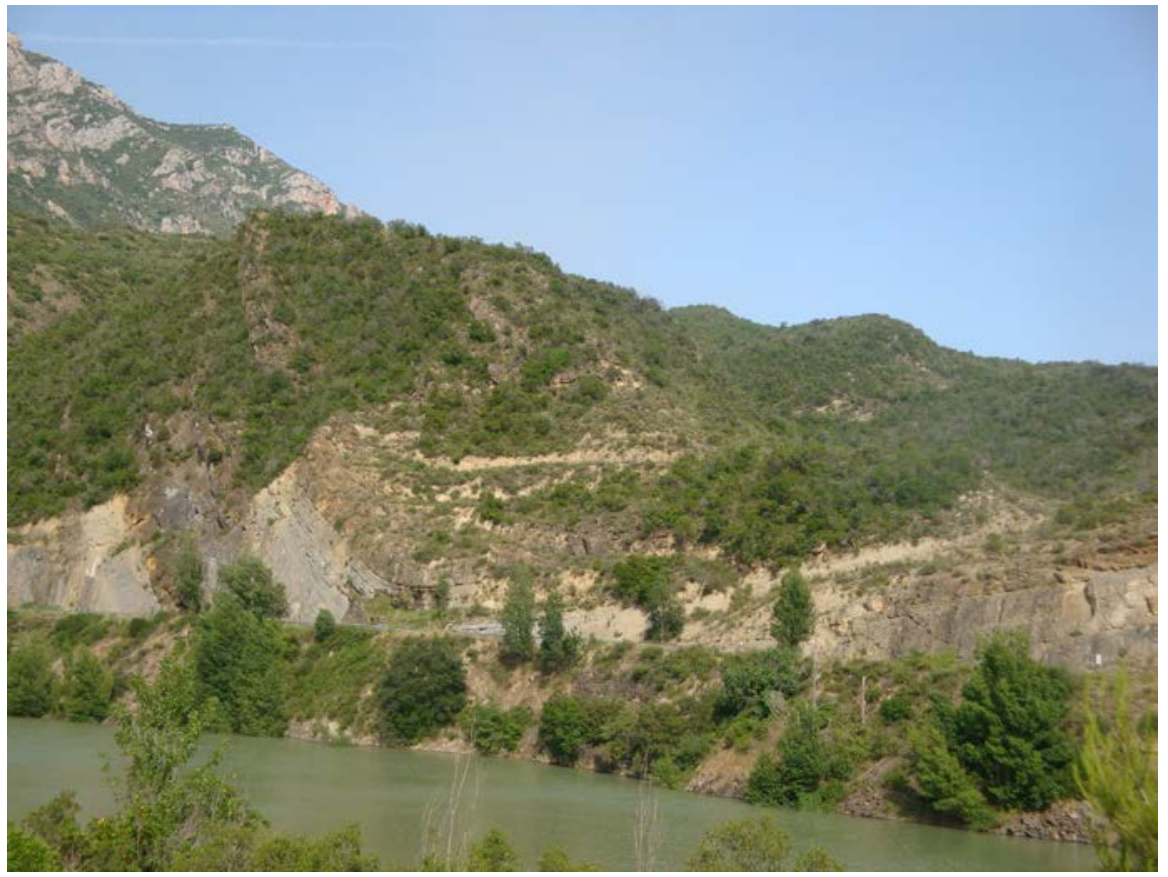

Fotografia 5. Un altre aspecte del Sinclinal d'Ager, de l'extrem septentrional del Mantell de la Serra de Sant Mamet. A l'esquerra de la fotografia es veuen els relleus del Montsec, del Mantell del Montsec, el qual encavalca al primer mantell esmentat.

\subsection{Parada 8. FONT DE LES BAGASSES, (terme de Camarasa - la Fonòloga, comarca de la Noguera). (Full 290).}

Després de realitzar la parada anterior, cal retornar cap a la carretera C - 13 (després de creuar el Pallaresa i la cua de l'embassament de Camarasa). En arribar de nou a la cruïlla es poden veure els material eocènics gairebé verticals. Després, ens caldrà seguir riu amunt per la carretera C - 13, fins arribar a l'Àrea d'Aparcament de la Font de les Bagasses. Aquí farem la darrera aturada del recorregut d'aquest itinerari, a uns 3'5 $\mathrm{Km}$ de l'anterior aturada.

En aquest recorregut, hem travessat l'encavalcament del Mantell del Montsec, sobre el Mantell de la Serra de Sant Mamet. Així els materials mesozoics del primer mantell, es superposen sobre els cenozoics del segon; concretament sobre el flanc septentrional del Sinclinal d'Ager, el qual es troba pràcticament verticalitzat, com es pot veure a la mateixa cruïlla de carreteres.

Així, a partir d'aquest contacte, haurem començat a trobar afloraments dels materials mesozoics del Mantell del Montsec; d'aquesta forma, haurem trobat nivells de calcolutites, gresos i calcàries del Juràssic. Aquestes darreres són les qual es fan molt més evidents i sovint son calcàries dolomítiques.

Així, ara a l'indret de la present aturada, es pot veure un aflorament espectacular d'aquests materials carbonatats juràssics, per sobre dels quals es veuen potents nivells de calcaries que ja pertanyen al Cretàcic.

Des d'aquest indret, es pot veure com destaquen, a mitja alçada, els materials carbonatats calcaris i dolomítics del Dogger, del Juràssic Mig. (fotografia 6). 


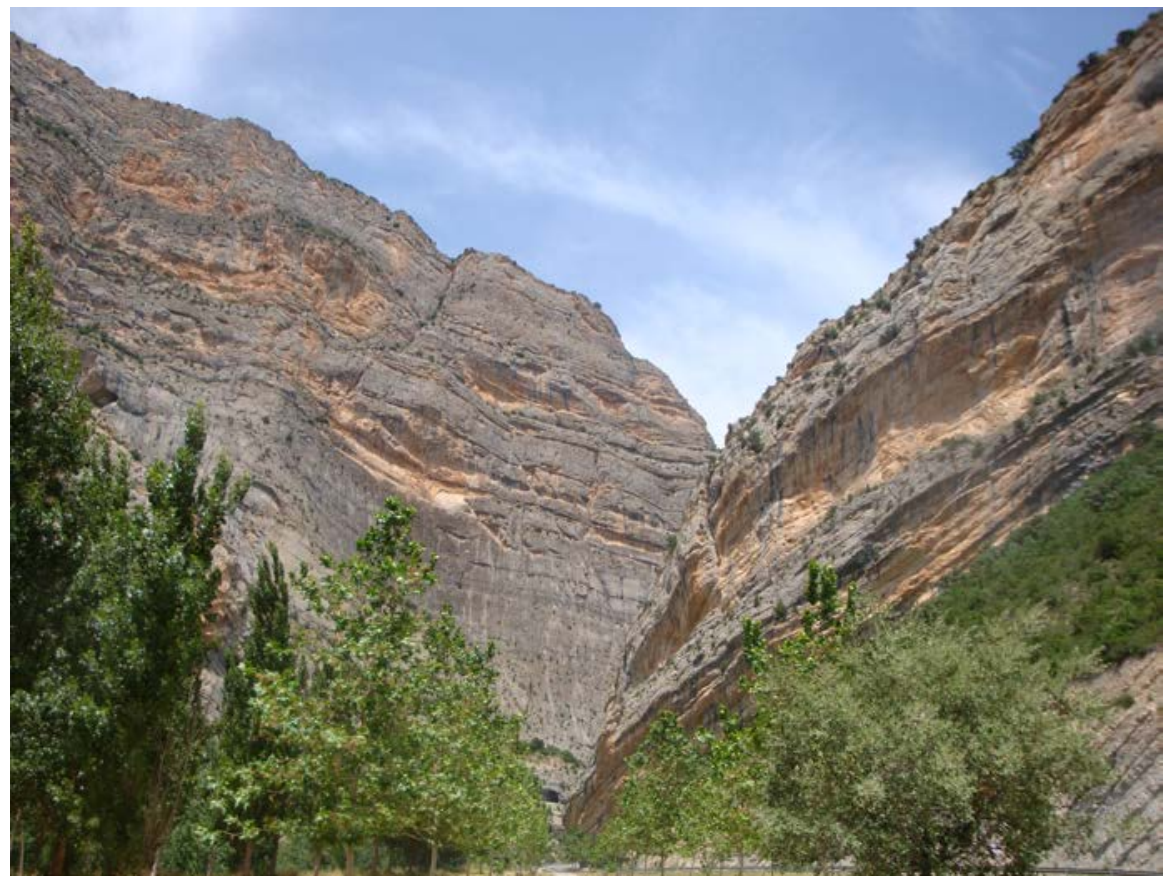

Fotografia 6. Les calcaries i dolomies del Juràssic i del Cretàcic (a la part superior), del Montsec, Mantell del Montsec, des de la Font de les Bagasses.

\subsection{Parada 9 - CONDICIONAL. FORAT DE L'OR, PAS DE TERRADETS (terme de Camarasa - la Fonòloga, comarca de la Noguera). (Full 290).}

Després de realitzar la parada anterior, si śescau, es pot realitzar un curt trajecte a peu, per la carretera C - 13, per tal d'arribar fins l'indret on hi ha el conegut Forat de I'Or. Per anar-hi, es caldrà caminar poc menys de o' $5 \mathrm{Km}$.

En aquest recorregut, hem anat trobant afloraments dels materials juràssics esmentats a I'aturada anterior. Aquests són els materials que apareixen a l'indret de la present aturada. En concret, es veuen aquí els materials carbonatats del Dogger.

En aquest indret hi ha una surgència d'aigua, que de vegades és força espectacular, saltant inclús a la carretera i arribant al riu. Aquest element forma part d'una interessant xarxa kàrstica situada dintre del Montsec.

Per altra banda, prop d'on som ara, comença la part més estreta del conegut Pas de Terradets. Tanmateix, en arribar-hi a aquest indret, es passa de la comarca de la Noguera a la del Pallars Jussà.

En aquest indret finalitza el recorregut de l'itinerari 


\section{Bibliografia}

GUIMERÀ, J. et altri (1992).- Geologia (II), Història Natural dels Països Catalans, Vol.2, 547 pag. Enciclopèdia Catalana, S.A. Barcelona.

IGME (1970).- Mapa Geológico de España, a escala 1.200.000 (Síntesis de la Cartografia existente). Full i memòria $n^{\circ}$ 24, Berga. Inst. Geol. Minero de España. Madrid.

IGME (1994).- Mapa Geológico de España a escala 1:50.000 (Plan Magna). Fulla i Memòria $\mathrm{n}^{\circ}$ 252 (Tremp). Inst. GeoMinero y Tecnol. España. Minist. Indústria. Madrid.

MATA - PERELLÓ, J.M. (1991).- Els Minerals de Catalunya. Arxius de la Secció de Ciències, t. XCIII, 442 pag. Institut d'Estudis Catalans. Barcelona.

MATA - PERELLÓ, J.M. (1996).- Itinerari geològico-mineralògic per la Noguera: des Montclar d'Urgell a Santa Maria de Meià, Inèdit, 13pag. Manresa.

MATA-PERELLÓ, J.M. (1999).- Recerca geològica i mineralògica per les comarques de la Noguera i del Pallars Jussà: des del Pont d'Alentorn a Vilanova de Meià, i des del Pas Nou al congost d’Erinyà. Revista Algeps, nº 87, 10 pag. Manresa.

MATA-PERELLÓ, J.M. (2002).- Recorregut de recerca geològica i mineralògica per la comarca del Pallars Jussà: des de la Font de les Bagasses a l'Estany de Montcortès, tot passant per Basturs. Inèdit. 12 pàgines. Manresa.

MATA-PERELLÓ, J.M. (2005).- Recorregut geològic i mineralògic per la comarca de la Noguera: des de Bellmunt d'Urgell a Cubells; i des de Camarasa al Pas de Terradets. Inèdit. 8 pàgines. Manresa.

MATA-PERELLÓ, J.M. (2010).- Recorregut de recerca geològica i mineralògica per les comarques del Pallars Jussà i de la Noguera: des de la Pobla de Segur al Pas de Terradets i a l'Aiguabarreig de Camarasa. Inèdit. 10 pàgines. Manresa.

MATA-PERELLÓ, J.M. (2011).- Recorregut de recerca geològica per la comarca de la Noguera: des de Cubells a la Foradada, Artesa de Segre i a Vilanova de Meià. Inèdit. 12 pàgines Manresa.

MATA-PERELLÓ, J.M. (2012).- Recorregut geològic, geonaturalístic i mineralògic per la comarca de la Noguera: des d'Ager a Sant Oïsme, al Doll, a I'Aiguabarreig i a Vilanova de Meià. Inèdit. 8 pàgines Manresa.

MATA-PERELLÓ, J.M. (2014).- Recorregut de recerca geològica i mineralògica per les comarques del Pallars Jussà i de la Noguera: des de Talarn a Tremp, Suterranya, Sant Salvador de Toló i a Vilanova de Meià. Inèdit. 14 pàgines. Manresa.

RIBA, O. et altri (1976).- Geografia Física dels Països Catalans, Edit. Ketres, 254 pàgines. Barcelona.

ROSELL SANUI, J. (1970).- Explicació del Mapa Geològic, a escala 1:50.000, corresponent al full $n^{\circ} 252$ (Tremp). Mapa Geológico de España. Inst. Geológico y Minero de España. Madrid. 